\title{
Spectral decomposition of remote sensing reflectance variance due to the spatial variability from ocean color and high-resolution satellite sensors
}

\author{
Eder Herrera Estrella, ${ }^{\text {a,b,c }}$ Alexander Gilerson, ${ }^{\text {a,b,c, } *}$ Robert Foster $\odot,{ }^{d}$ and \\ Philipp Groetsch ${ }^{a}$ \\ ${ }^{a}$ The City College of New York, CUNY, Optical Remote Sensing Laboratory, New York, \\ United States \\ ${ }^{\mathrm{b}}$ The Graduate Center, CUNY, Earth and Environmental Sciences, New York, United States \\ ${ }^{c}$ NOAA - Cooperative Science Center for Earth System Sciences and Remote Sensing \\ Technologies, New York, United States \\ ${ }^{\mathrm{d} N a v a l}$ Research Laboratory, Remote Sensing Division, Washington, DC, United States
}

\begin{abstract}
The variability of the remote sensing reflectance, $R_{\mathrm{rs}}$, now routinely retrieved from ocean color (OC) and high spatial resolution sensors, is often used to characterize water variability due to changes in inherent optical properties of the water body. At the same time, $R_{\mathrm{rs}}$ is partially variable because of uncertainties in its retrieval in the process of atmospheric correction. Using data from SNPP-VIIRS and Landsat-8 OLI sensors, the contribution of the main components to the variance of $R_{\mathrm{rs}}$ due to its spatial variability is determined based on a model in which variances were considered proportional to the mean values of the corresponding components. It is shown that there is practically no spatial variability in the open ocean waters and water variability is proportional to the spatial resolution of the sensor in coastal waters. Variances due to surface effects, inaccuracies of aerosol models, and sunglint can contribute significantly to $R_{\mathrm{rs}}$ variance, which characterizes $R_{\mathrm{rs}}$ spatial variability, with variances due to the water variability itself often being significantly smaller. (C) The Authors. Published by SPIE under a Creative Commons Attribution 4.0 Unported License. Distribution or reproduction of this work in whole or in part requires full attribution of the original publication, including its DOI. [DOI: 10.1117/1.JRS.15.024522]
\end{abstract}

Keywords: remote sensing reflectance; uncertainties; spatial resolution.

Paper 200881 received Dec. 16, 2020; accepted for publication Jun. 4, 2021; published online Jun. 25, 2021.

\section{Introduction}

Ocean color (OC) is indicative of ocean health and biochemistry and for that reason is listed as an essential climate variable (ECV). ${ }^{1}$ The color of a water body is determined by scattering and absorption by pure water and its natural constituents, such as phytoplankton, other particles, and colored dissolved organic matter (CDOM) ${ }^{2}$ Some phytoplankton species form harmful algal blooms, which can negatively affect human and marine life and often have severe repercussions on a range of industries. ${ }^{3}$ Typically, $<10 \%$ of the top of the atmosphere (TOA) radiance is due to the water signal at sea level, ${ }^{4}$ with the remainder originating from scattering processes in the atmosphere and reflections of Sun and sky on the wave-roughened water surface. It is paramount to accurately estimate radiances at the surface level from the ones at the TOA as uncertainties propagate into the retrieval of water parameters, characteristics of in-water particulates, concentrations of chlorophyll-a, and detection of algal blooms. ${ }^{5}$

Atmospheric correction uncertainties stem at least partially from the estimation of aerosol models ${ }^{6,7}$ and air-water interface corrections, ${ }^{8-10}$ with the latter due to sky and Sun light reflections at the wind-roughened air-water interface. Glint correction uncertainties often have a stronger impact on retrievals in coastal waters with low water reflectance values in the blue bands. ${ }^{1-14}$ Currently, high uncertainties in blue reflectance observations are widely acknowledged. ${ }^{5,14,15}$ However, little is known about the specific dependencies of uncertainties

*Address all correspondence to Alexander Gilerson, gilerson@ccny.cuny.edu 
concerning their spectral and scaling behavior in various water areas and their dependence on meteorological conditions.

Uncertainties of the remote sensing reflectance, $R_{\mathrm{rs}}$, are estimated by comparison of the water parameters determined from the satellite imagery with the "true" values, which can be determined, for an example, in very uniform clear waters in which all water parameters can be connected to the concentration of chlorophyll-a, $[\mathrm{Chl}] .{ }^{16} \mathrm{~A}$ second approach is to compare data from satellite with field measurements from the towers in the ocean, the Aerosol Robotic Network for Ocean Color (AERONET-OC ${ }^{17,18}$ ) sites or from ships. ${ }^{19}$ Such comparisons can be carried out in a wide range of waters; however, they are associated with multiple additional uncertainties, which are related to the quality of field measurements themselves, ${ }^{20}$ water variability inside pixels, and time difference between in situ and satellite data. In another approach that uses Monte Carlo (MC) simulations for sea-viewing wide field-of-view sensor (SeaWiFS) observations, ${ }^{21}$ the retrieval process for the remote sensing reflectance, $R_{\mathrm{rs}}$, was repeated 1000 times, and uncertainties in $R_{\mathrm{rs}}$ were then estimated as the "standard deviation of the 1000 perturbed $R_{\mathrm{rs}}$ retrievals in each band." This derived uncertainty was interpreted "as the precision of the $R_{\mathrm{rs}}$ retrieval due to instrument noise."

The standard deviation of $R_{\mathrm{rs}}$ due to its spatial variability in the specific area, $\sigma_{\text {spat }}$, represents the changes related to the variability of water inherent optical properties and together with the coefficient of variation (CV) is of interest to the OC community, especially as a function of the satellite spatial resolution or ground sampling distance (GSD). ${ }^{22}$ However, $\sigma_{\text {spat }}$ is contaminated by other components of $R_{\mathrm{rs}}$ uncertainites and should be rectified before being considered a proxy for water variability. $\sigma_{\text {spat }}$ is also a part of the full $R_{\mathrm{rs}}$ uncertainty and can be considered the precision of the $R_{\mathrm{rs}}$ retrieval due to spatial variability for the specific type of the atmospheric correction process.

In this work, we focus on the spectral behavior of $\sigma_{\text {spat }}$ and its components and their dependence on GSD through the analysis of satellite data from the Visible Infrared Imaging Radiometer Suite (VIIRS) on the Suomi National Polar-orbiting Partnership (SNPP) platform and Landsat-8 Operational Land Imager. First attempts in this direction were made through the analysis of VIIRS satellite data, ${ }^{23}$ demonstrating dependence of spectra and magnitude of $\sigma_{\text {spat }}$ on GSD, which were attributed to the surface and water conditions. This work will expand on that study by considering a broad set of parameters involved in the atmospheric correction process.

\section{Theoretical Considerations}

The main radiometric quantity in the processing of satellite data is remote sensing reflectance, $R_{\mathrm{rs}}$, which is defined as the ratio of the water-leaving radiance to the downwelling irradiance at the sea surface, $R_{\mathrm{rs}}(\lambda)=L_{w}(\lambda) / E_{d}(\lambda)$, where $L_{w}(\lambda)$ is the water leaving radiance, $E_{d}(\lambda)$ is the downwelling irradiance, and $\lambda$ is the wavelength. At the TOA, the total radiance, $L_{t}(\lambda)$, is represented as ${ }^{6}$

$$
L_{t}(\lambda)=L_{r}(\lambda)+L_{a}(\lambda)+L_{g}(\lambda)+t(\lambda) L_{w o}(\lambda)
$$

where $L_{r}(\lambda)$ is the radiance due the Rayleigh scattering including surface effects, $L_{a}(\lambda)$ is the radiance due to the aerosol scattering, $L_{g}(\lambda)$ is the radiance due to the sun glint from the water surface, $L_{w o}(\lambda)$ is the water leaving radiance in the process of detection, and $t(\lambda)$ is the diffuse transmittance of light from the water surface to the TOA. $L_{t}(\lambda)$ has uncertainties due to all of these components and sensor noise. In the process of the retrieval of the water leaving radiance

$$
L_{w}(\lambda)=\left(L_{t}(\lambda)-L_{r}(\lambda)-L_{a}(\lambda)-L_{g}(\lambda)\right) / t(\lambda)
$$

In addition, $L_{r}(\lambda)$ can be divided into the radiance from the Rayleigh scattering in the atmosphere, $L_{R}(\lambda)$, and the radiance due to the reflectance from the ocean surface, $L_{\text {surf }}(\lambda)$

$$
L_{r}(\lambda)=L_{R}(\lambda)+t(\lambda) L_{\text {surf }}(\lambda)
$$

where $L_{\text {surf }}(\lambda)=L_{\text {sky }}(\lambda) * \rho, L_{\text {sky }}(\lambda)$ is the sky radiance and $\rho$ is the reflectance coefficient from the water surface. In the satellite atmospheric correction procedure, averaged surface effects are considered in the vector radiative transfer (VRT) equations, which are based on Cox-Munk distributions. $^{8,24}$ However, each satellite image captures a specific snapshot of the ocean, 
in which the actual spatial average of the light field reflected from the wave facets may not exactly match the average predicted by the VRT model. The actual signal may have its own features due to instantaneous water and atmospheric conditions, spatial scales in the area, or simplifying assumptions made within the VRT model, as Cox-Munk model is not necessarily valid for waters in coastal areas.

Uncertainties from the abovementioned components need to be taken into account. So, normalizing by the downwelling irradiance, $E_{d}(\lambda)$, uncertainty in remote sensing reflectance $\sigma$ in $\mathrm{sr}^{-1}$ is determined from

$$
\sigma^{2}=\left(\sigma_{t}^{2}+\sigma_{R}^{2}+\sigma_{a}^{2}+\sigma_{g}^{2}\right) / t^{2}+\sigma_{\text {surf }}^{2}+\sigma_{\text {water }}^{2}+\sigma_{\text {noise }}^{2}
$$

where $\sigma_{t}^{2}, \sigma_{R}^{2}, \sigma_{a}^{2}, \sigma_{g}^{2}, \sigma_{\text {surf }}^{2}$ are variances of normalized $L_{t}(\lambda), L_{R}(\lambda), L_{a}(\lambda), L_{g}(\lambda), L_{\text {surf }}(\lambda)$ and $\sigma_{\text {water }}^{2}(\lambda)$ and $\sigma_{\text {noise }}^{2}(\lambda)$ are variances due to water variability and sensor noise respectively.

Variances for the quantities at TOA $\sigma_{t}^{2}, \sigma_{R}^{2}, \sigma_{a}^{2}, \sigma_{g}^{2}$ are divided by $t^{2}$ in accordance with Eqs. (1) and (2); $\sigma_{\text {noise }}^{2}$ has $1 / t^{2}$ in its definition. ${ }^{25}$

We assumed that all standard deviations (except $\sigma_{\text {noise }}$ ) in Eq. (4) as a first approximation, are spectrally proportional to the corresponding mean values of normalized radiances with $k$ as proportionality coefficients $\left(k_{t}, k_{R}, k_{a}, k_{g}, k_{s}, k_{R_{\mathrm{rs}}}\right.$, and $k_{n}$ are the fitting coefficients for $L_{t}(\lambda)$, $L_{R}(\lambda), L_{a}(\lambda), L_{g}(\lambda), L_{\text {surf }}(\lambda)$ normalized by $E_{d}(\lambda), R_{r s}(\lambda)$ and $\sigma_{\text {noise }}$ respectively):

$$
\begin{aligned}
\sigma^{2}= & \left(\left(k_{t} L_{t} / E_{d}\right)^{2}+\left(k_{R} L_{R} / E_{d}\right)^{2}+\left(k_{a} L_{a} / E_{d}\right)^{2}+\left(k_{g} L_{g} / E_{d}\right)^{2}\right) / t^{2} \\
& +\left(k_{s} S * 0.025\right)^{2}+\left(k_{R_{\mathrm{rs}}} R_{r s}\right)^{2}+\left(k_{n} \sigma_{\text {noise }}\right)^{2}
\end{aligned}
$$

where

$$
\begin{gathered}
L_{R}(\lambda)=F_{0}(\lambda) \tau_{R}(\lambda) * 0.75 *\left(1+\cos ^{2} \Theta\right) /(4 \pi \cos \theta), \\
L_{a}(\lambda)=F_{0}(\lambda) \tau_{a}(\lambda) P_{a} /(4 \pi \cos \theta), \\
L_{g}(\lambda)=F_{0}(\lambda) T_{0}(\lambda) T(\lambda) * 0.005, \\
E_{d}(\lambda)=F_{0}(\lambda) t_{0}(\lambda) \cos \theta_{0}, \\
L_{\text {surf }}(\lambda)=\rho L_{\text {sky }}(\lambda) ; \quad S(\lambda)=L_{\text {sky }}(\lambda) / E_{d}(\lambda), \\
L_{t}(\lambda)=L_{R}(\lambda)+L_{a}(\lambda)+t(\lambda)\left(L_{S}(\lambda)+R_{r s}(\lambda) * E_{d}(\lambda)\right),
\end{gathered}
$$

and in Eq. (6a), $F_{0}(\lambda)$ is the extraterrestrial irradiance, $\tau_{R}(\lambda)$ is the Rayleigh optical thickness, $\theta$ is the sensor zenith angle, and $\Theta$ is the scattering angle, which is the angle between solar and viewing directions; in Eq. (6b, $\tau_{a}(\lambda)$ is the aerosol optical thickness, $P_{a}$ is the scattering function for aerosols assumed as $P_{a}=0.3$ (without considering its possible spectral dependence) based on the analysis for two AERONET-OC stations; ${ }^{26}$ in Eq. (6c), $T_{0}(\lambda)$ and $T(\lambda)$ are the direct transmittance coefficients for TOA to surface and surface to TOA, respectively, and 0.005 is the threshold for glint detection ${ }^{9}, L_{\mathrm{GN}}$, in $\mathrm{sr}^{-1}$; in Eq. $6(\mathrm{~d}), \theta_{0}$ and $t_{0}(\lambda)$ are the Sun zenith angle and the corresponding diffuse transmittance from the TOA to the water surface, respectively; in Eq. (6e), a representative normalized sky reflectance, $S=L_{\text {sky }} / E_{d}$, was simulated by the VRT RayXP $\operatorname{code}^{27}$ for the Sun zenith angle $\theta_{0}=42 \mathrm{deg}$ at a viewing zenith angle of $40 \mathrm{deg}$, aerosol optical thickness at $443 \mathrm{~nm}$ AOT $_{443 \mathrm{~nm}}=0.13$ and Angstrom coefficient 1.0, parameters that are very close to the average ones for all observations and are used throughout this study. Sky radiance, $L_{\text {sky }}$, differs from scene to scene, whereas the normalized radiance, $L_{\text {sky }} / E_{d}$, has much less variability; the reflectance coefficient was considered to be $\rho=0.025$, which is the typical reflectance coefficient at a $40 \mathrm{deg}$ viewing angle. It should be emphasized that the spectral shapes of the main components in Eqs. (6a)-(6e) are of primary interest; changes of values that were assumed constant in the model do not affect these shapes or the contribution of the corresponding uncertainties from these components to the total $\sigma^{2}(\lambda)$. The glint and noise components are included in the expression for the total variance [Eq. (4)] but were not included in the total radiance $L_{t}(\lambda)$ in Eq. (6f) since ideally their values should be zero. 


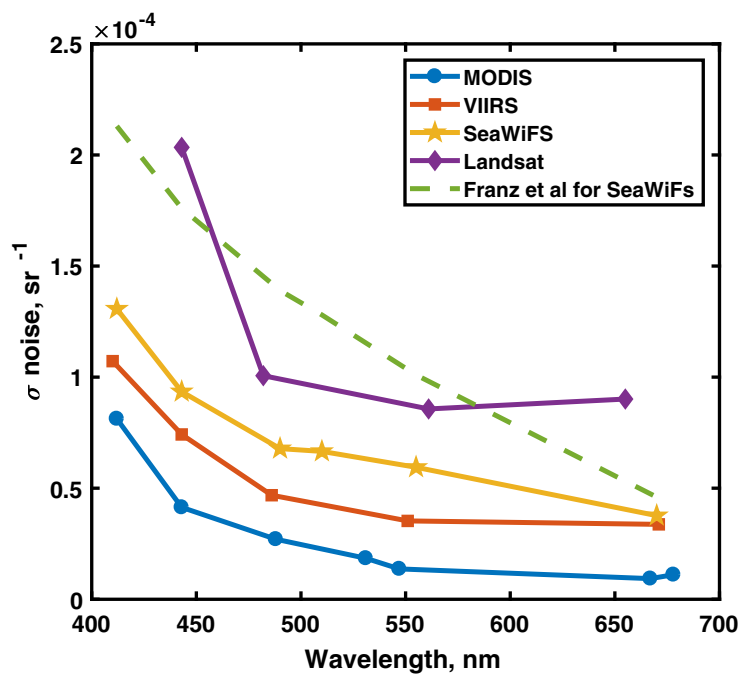

Fig. $1 \sigma_{\text {noise }}$ for several satellite sensors.

The model of Eqs. (5) and (6) can be used to analyze contributions of spectral components to the total $\sigma^{2}(\lambda)$ if the latter can be determined from the comparison of satellite - in situ data. Our current work is primarily focused on the contributions of the same spectral components but only to the variance $\sigma_{\text {spat }}^{2}$ referring to the $R_{\mathrm{rs}}(\lambda)$ spatial variability in the area, which can characterize water variability, so $\sigma(\lambda)$ was replaced by $\sigma_{\text {spat }}(\lambda)$ in Eq. (5) and in the further analysis.

$\sigma_{\text {noise }}$ was determined based on typical radiance at TOA $L_{t}(\lambda)$, signal-to-noise ratio (SNR), and transmittance coefficients $t_{0}(\lambda)$ for the TOA to the surface and $t(\lambda)$ for the surface to TOA. ${ }^{25}$

$\sigma_{\text {noise }}$ for VIIRS, SeaWiFS, Moderate Resolution Imaging Spectroradiometer (MODIS), and Landsat 8 Operational Land Imager (OLI) with data taken from Refs. 16, 28, and 29 are shown in Fig. 1. A preliminary study ${ }^{23}$ showed that in moderately clear waters $\sigma_{\text {spat }}(\lambda)$ was close to the standard deviation spectrum, $\sigma_{F}$, determined by Franz and Karaköylü ${ }^{21}$ for SeaWiFS, and this spectrum was added for comparison.

Thus, in terms of the single pixel processing, noise can be a significant contributor to $\sigma_{\text {spat }}(\lambda)$, but with the often-used representation of data averaged over multiple pixels, this contribution is reduced inversely proportional to the square root of the number of pixels.

Mean spectra of $R_{\mathrm{rs}}(\lambda)$ and $\sigma_{\text {spat }}(\lambda)$, quantities from Eq. (6) were determined by processing of VIIRS data in the specific area with the wind speed $W$ in each of the ranges $W<3 \mathrm{~m} / \mathrm{s}$, $3<W<5 \mathrm{~m} / \mathrm{s}$, and $W>5 \mathrm{~m} / \mathrm{s}$. With these parameters calculated for a scene, a nonlinear least-squares fit was carried out in MATLAB using the Levenberg-Marquardt technique ${ }^{30,31}$ to determine the respective values of $k$ coefficients for each scene or set of scenes, taking advantage of the differences in the spectra of $\sigma_{\text {spat }}(\lambda)$ components in Eq. (5). These coefficients are assumed to be representative of the respective contributions of the atmospheric, water, and sky reflection components to the observed spatial scale variance $\sigma_{\mathrm{spat}}^{2}(\lambda)$ of the $R_{\mathrm{rs}}$ since $R_{\mathrm{rs}}$ is the result of the processing through the atmospheric correction. By this operation, the actual contribution of $\sigma_{\text {water }}(\lambda)$ to $\sigma_{\text {spat }}(\lambda)$ is determined at different spatial resolutions since $\sigma_{\text {water }}(\lambda)$ better characterizes water optical variability than $\sigma_{\text {spat }}(\lambda)$. Since, as was mentioned before, in the clear waters, the $\sigma_{\text {spat }}(\lambda)$ spectrum was very close to $\sigma_{F}(\lambda),{ }^{21}$ the latter will be shown as a benchmark for the results given below that are related to $\sigma_{\text {spat }}(\lambda)$.

\section{VIIRS and Landsat OLI Satellite Data and Study Areas}

\subsection{VIIRS Data}

Satellite Level 2 imagery (2018.0) for VIIRS was downloaded from the NASA Ocean Color website. ${ }^{6,32-34}$ Observations were retrieved for the period of January 2012 to December 2018 
for three AERONET-OC site areas: the Long Island Sound Coastal Observatory (LISCO), WaveCIS site in the Gulf of Mexico, University of South California (USC) site in California waters, and the area of Marine Optical Buoy (MOBY) in Hawaii. NASA Level 2 data files for VIIRS include geophysical products of the atmosphere and ocean, such as aerosol optical thickness (AOT), remote sensing reflectance, $R_{r s}(\lambda)$, and the level 2 quality flags. The Sun zenith angle, sensor viewing angle, and sensor azimuth angle were used to determine radiances and irradiance in Eq. (6). The VIIRS data have a nadir resolution of $750 \mathrm{~m}$. Pixels used for matchup comparison were averaged over three spatial resolutions $(3 \times 3,5 \times 5$, and $7 \times 7$ pixel boxes), centered at the in-situ observation location, ${ }^{35}$ and the standard deviation between pixels was recorded. Pixels flagged by at least one of the following conditions were excluded: land, cloud, failure in atmospheric correction, stray light (except for LISCO), bad navigation quality, high or moderate glint, negative Rayleigh-corrected radiance, negative water-leaving radiance, viewing angle greater than $60 \mathrm{deg}$, and solar zenith angle greater than $70 \mathrm{deg}$. With this selection of study areas, the whole range of water types from very coastal in LISCO to very clear in Hawaii with moderate coastal in the Gulf of Mexico are covered. The analysis is carried out at VIIRS visible wavelengths $410,443,486,551$, and $671 \mathrm{~nm}$.

\subsection{Landsat-8 OLI Data}

The Landsat- 8 OLI has a resolution of $30 \mathrm{~m}$ and a field-of-view of $15 \mathrm{deg}( \pm 7.5 \mathrm{deg}$ from nadir). To analyze the dependence of uncertainties on various scales, the aquatic reflectance product was used. OLI bands are centered at 440, 480, 560, and $660 \mathrm{~nm}$ wavelengths. The L2 data were downloaded from the USGS Earth Resources Observation and Science Center Science Processing Architecture on Demand Interface website ${ }^{36}$ for the period 2013 to 2019. $R_{\mathrm{rs}}(\lambda)$ was calculated by dividing the dimensionless aquatic reflectance by $\pi$ and was taken for those imageries that pass the selection by the level 2 quality flags. Pixels flagged by at least one

(a)

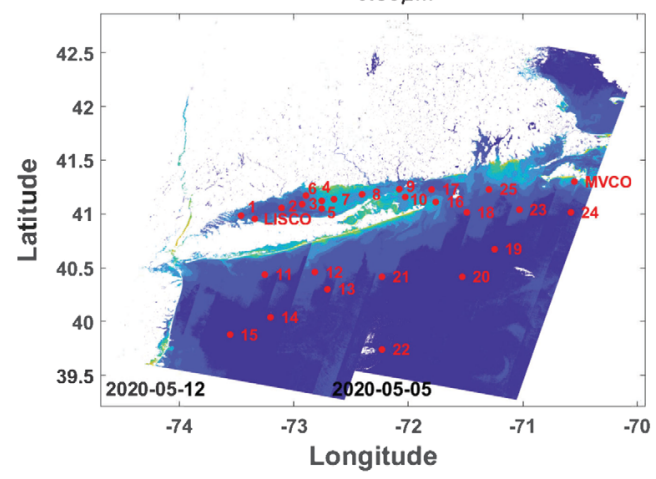

(c)

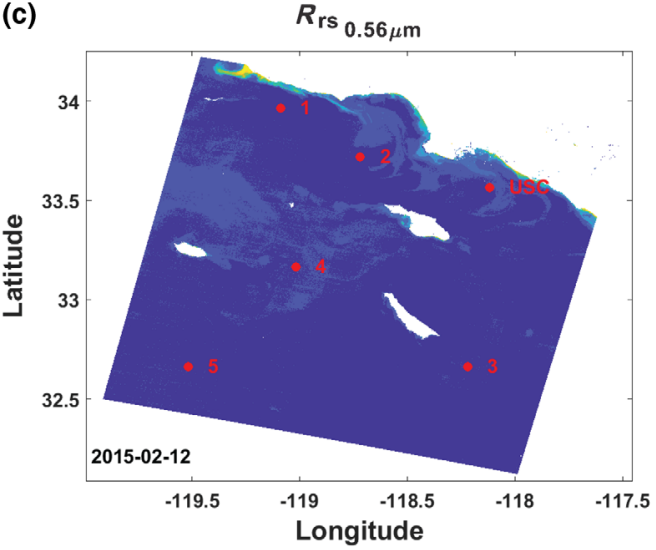

(b)

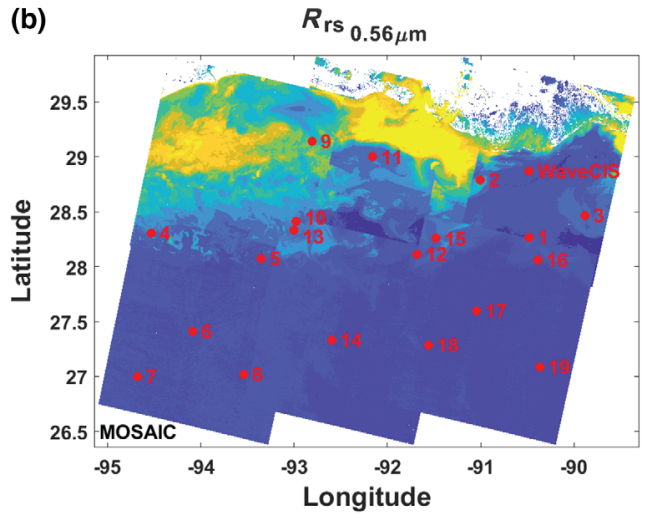

(d)

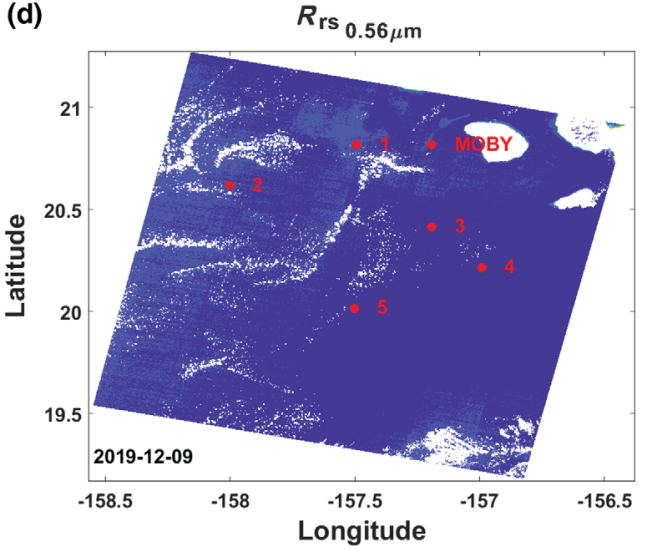

Fig. 2 Areas and scenes of study: (a) Long Island Sound (LIS) and NY Harbor, (b) Gulf of Mexico, (c) California waters, and (d) MOBY area, Hawaii. 
of the following conditions were excluded: land, cloud, failure in atmospheric correction, bad navigation quality, high or moderate glint, sea ice, viewing angle greater than $60 \mathrm{deg}$, and solar zenith angle greater than $70 \mathrm{deg}$. For each spatial resolution, $R_{\mathrm{rs}}(\lambda)$ was averaged, and the standard deviation was calculated. Nine spatial resolutions were implemented for each imagery with the following square pixel box scale: $3,7,19,31,35,51,75,125$, and 175 pixels $(90,210,570$, 930, 1050, 1530, 2250, 3750, and $5250 \mathrm{~m}$, at nadir). Atmospheric correction for $\mathrm{OLI}^{37,38}$ was implemented across $7 \times 7$ pixels to minimize noise effects, which need to be considered in the dependence of various parameters on the spatial resolution.

In both VIIRS and OLI processing, $R_{\mathrm{rs}}(\lambda)$ spectra with $R_{\mathrm{rs}}(412)>0.006$ water were considered open ocean; otherwise, they were considered coastal water area cases. Spectra with $R_{\mathrm{rs}}(412)<0$, which are typically due to the very inaccurate aerosol model in the atmospheric correction, were not included in the processing. Such cases require advanced atmospheric correction procedures, ${ }^{39}$ a discussion of which is outside the scope of this work. The areas of study and scenes analyzed from OLI imagery are shown in Fig. 2.

\section{Results}

\subsection{VIIRS Data Analysis}

There are seven $k$ coefficients in Eq. (5) that need to be determined from the fitting procedures, and VIIRS has only five bands in the visible part of the spectrum. Four terms were considered to be main potential contributors to $\sigma_{\text {spat }}(\lambda): \sigma_{R}(\lambda), \sigma_{a}(\lambda), \sigma_{\text {surf }}(\lambda)$, and $\sigma_{\text {water }}(\lambda)$; it was assumed that $\sigma_{t}(\lambda)$ was represented by its components and that the impact of two other terms, $\sigma_{g}(\lambda)$ and $\sigma_{\text {noise }}(\lambda)$, was analyzed by adding one of them as a fifth term. It was found that the impact of noise $\sigma_{\text {noise }}(\lambda)$ was small and the contribution of the glint component $\sigma_{g}(\lambda)$ was much more pronounced. Further results are shown for the fitting with $\sigma_{g}(\lambda)$ being the fifth component. Typical spectra for all components involved normalized to the value at $412 \mathrm{~nm}$ are shown for the open ocean and coastal water station in Fig. 3. It should be emphasized that in Eq. (4) $\sigma_{R}^{2}$ and $\sigma_{a}^{2}$ are divided by the transmittance coefficient and $\sigma_{\text {surf }}^{2}$ is not, so a combination of Rayleigh and aerosol scattering contributions has a normalized spectrum that is different from the spectrum of surface effects, which is proportional to the sky radiance. For the open ocean, the MOBY site surface effects spectrum in Fig. 3(a) is very close to the normalized spectrum of $\sigma_{\text {spat }}(\lambda)$ and, as shown in Fig. 4, is practically the only component represented in the fitting procedure, with the $\sigma_{\text {surf }}(\lambda)$ and $\sigma_{\text {fit }}(\lambda)$ being undistinguishable for all three wind speed ranges and $\sigma_{\text {fit }}(\lambda)$ being the best fit of spectral components into $\sigma_{\text {spat }}(\lambda)$ with $k$ coefficients. These spectra are very close to the spectrum $\sigma_{F}(\lambda) .^{21}$ The surface component is also dominant at the USC site open ocean waters with a small contribution of $\sigma_{R}(\lambda)$ and $\sigma_{a}(\lambda)$ components. The corresponding spectra of $R_{r s}(\lambda)$ in
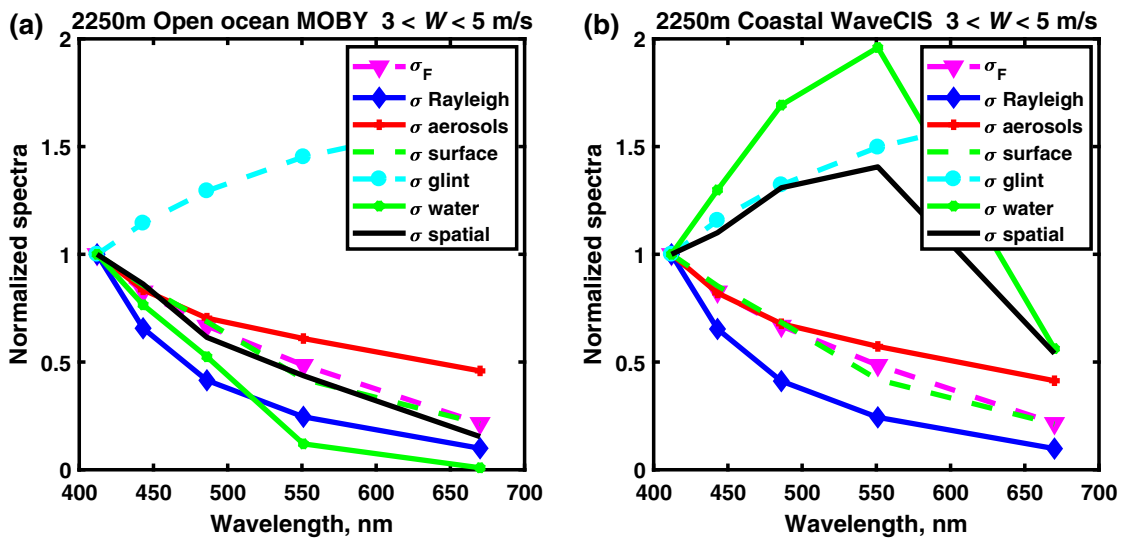

Fig. 3 Example spectra of $\sigma(\lambda)$ components normalized to their values at $412 \mathrm{~nm}$ : (a) open ocean waters and (b) coastal waters. 

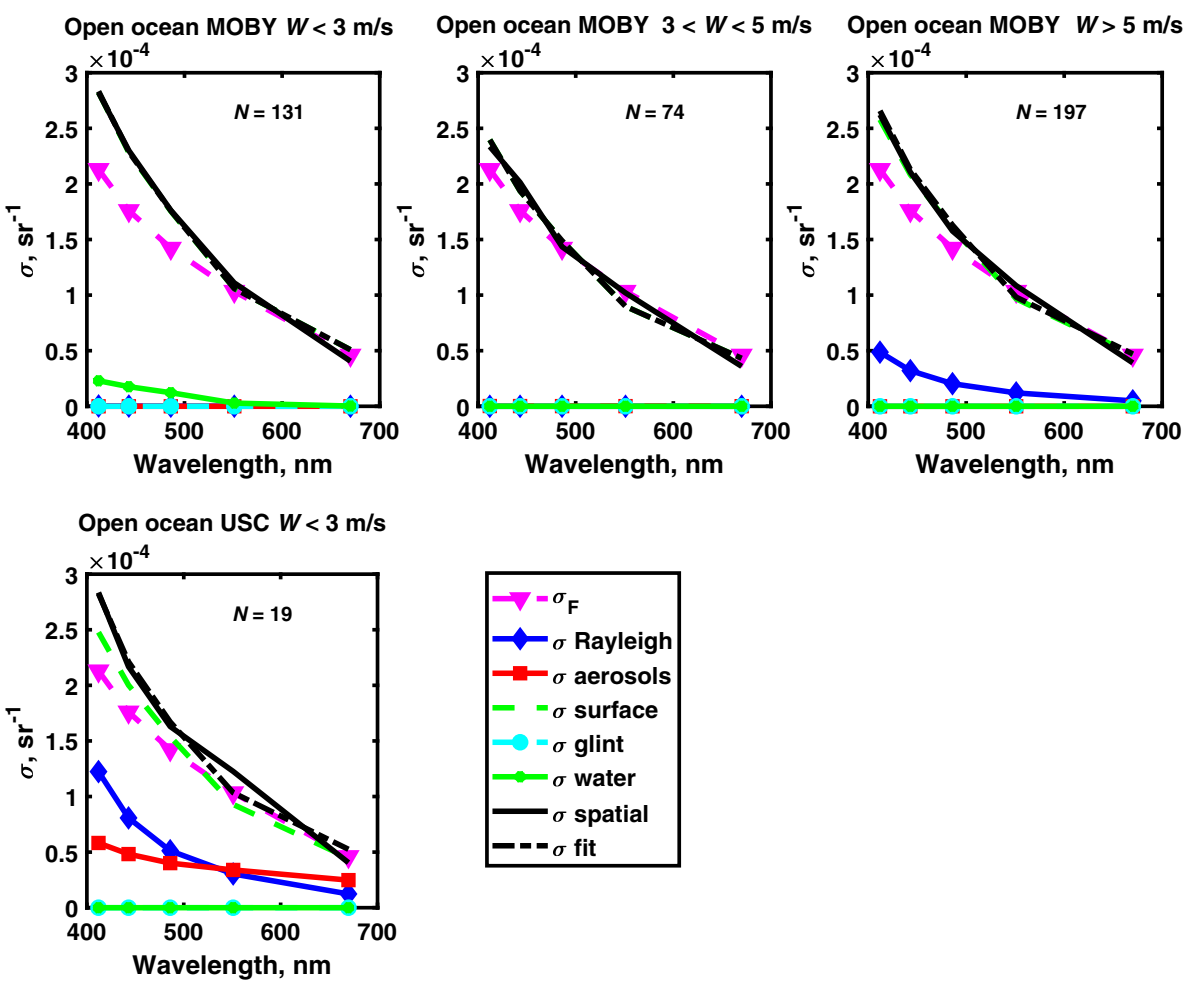

Fig. 4 Spectral components of $\sigma_{\text {spat }}(\lambda)$ in open ocean waters (MOBY and USC sites), VIIRS, $3 \times 3$ pixels.

the normalized form are also shown in Figs. 3(a) and 3(b) for open ocean and coastal waters, respectively, and in more detail in the Landsat OLI data in Figs. 10-12.

For the coastal waters in Fig. 5, there are some contributions from the Rayleigh and aerosol components (USC and WaveCIS sites), but the main effects are from the surface sky reflection, glint, and water variability. The changes of the $k$ coefficients related to all of these effects with the spatial resolution will be shown below together with Landsat data.

\subsection{Landsat Data Analysis and Comparison with VIIRS Data}

NASA atmospheric correction for Landsat OLI is similar to the atmospheric correction for VIIRS, ${ }^{37,38}$ and OLI fine spatial resolution permits an expanded analysis of $\sigma_{\text {spat }}(\lambda)$ dependence on GSD in a broad range. However, OLI has almost vertical viewing, whereas VIIRS viewing angles are in the range of $0 \mathrm{deg}$ to $56 \mathrm{deg}$, which can impact Sun and sky glint contributions. In terms of the application of Eqs. (4)-(6) of the proposed model to $\sigma_{\text {spat }}(\lambda)$ from OLI, the main difficulty is that OLI has only four bands (whereas VIIRS has five bands), which limits simultaneous analysis of the critical parameters' contributions. After preliminary analysis, $\sigma_{R}(\lambda)$ was excluded from the consideration, and only contributions of aerosol, $\sigma_{a}(\lambda)$, surface effects, $\sigma_{\text {surf }}(\lambda)$, sun glint, $\sigma_{g}(\lambda)$, and water variability, $\sigma_{\text {water }}(\lambda)$, were analyzed. Examples of the fitting procedures for open ocean waters near the Hawaii site and WaveCIS coastal site for three spatial resolutions are shown in Figs. 6 and 7. $\sigma_{\text {spat }}(\lambda)$ is small at low resolutions and gradually increases for higher resolutions being very close to $\sigma_{F}(\lambda)$, with main contributions being from surface effects and aerosol components in the open ocean waters.

At the WaveCIS site, there are clear contributions from all components, with increasing effects due to water variability proportional to the $R_{\mathrm{rs}}(\lambda)$ spectrum for higher GSD. Mean values of normalized radiances for different components in Eq. (6) vary significantly, so $k$ coefficients are given in Figs. 6 and 7 to demonstrate the contribution of components associated with these coefficients. 


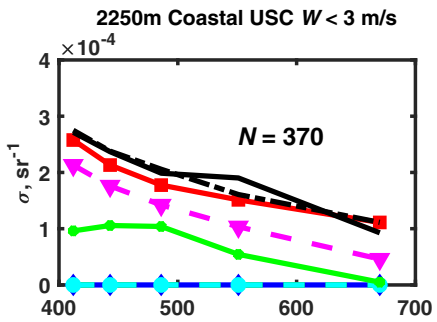

$2250 \mathrm{~m}$ Coastal WaveCIS $W<3 \mathrm{~m} / \mathrm{s}$
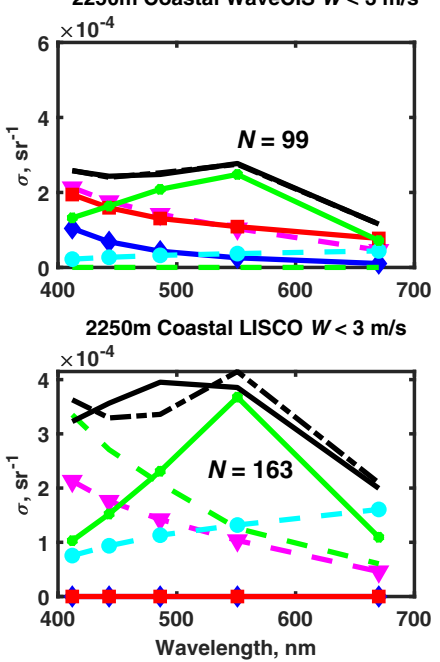

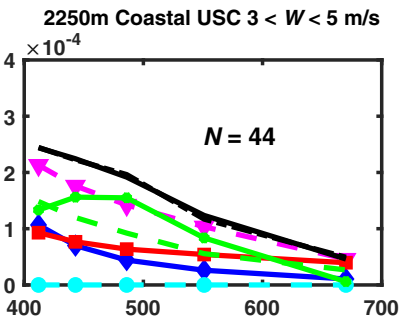

$2250 \mathrm{~m}$ Coastal WaveCIS $3<W<5 \mathrm{~m} / \mathrm{s}$

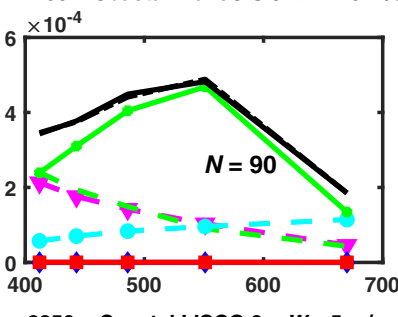

$2250 \mathrm{~m}$ Coastal LISCO $3<W<5 \mathrm{~m} / \mathrm{s}$

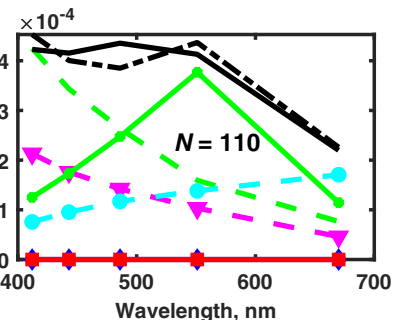

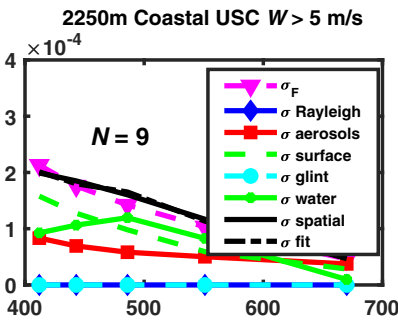

$2250 \mathrm{~m}$ Coastal WavecIS $W>5 \mathrm{~m} / \mathrm{s}$

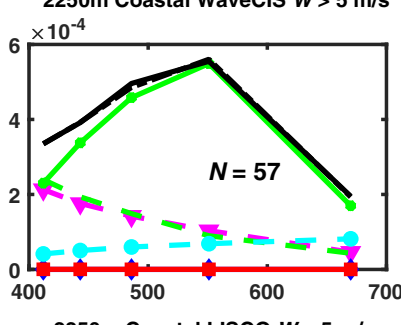

$2250 \mathrm{~m}$ Coastal LISCO $W>5 \mathrm{~m} / \mathrm{s}$

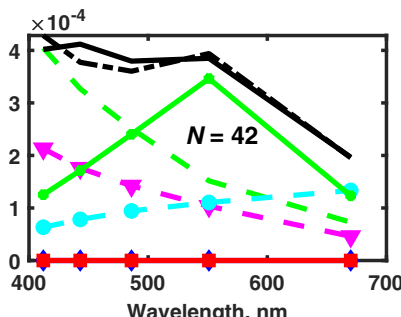

Fig. 5 Spectral components of $\sigma_{\text {spat }}(\lambda)$ in coastal waters (USC, WaveCIS, LISCO areas), VIIRS, $3 \times 3$ pixels.
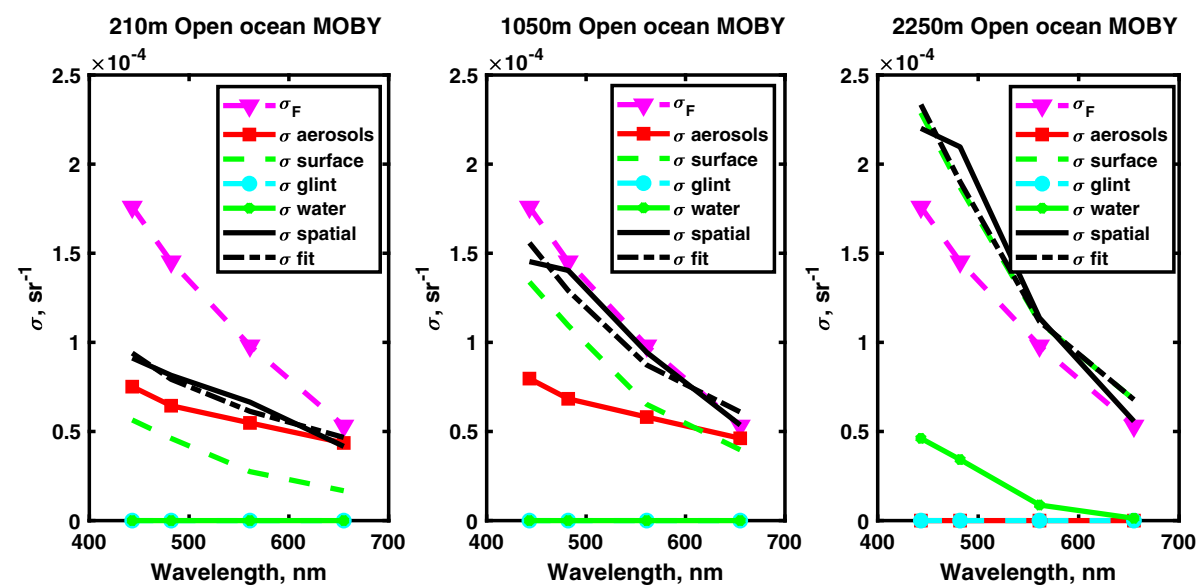

Fig. $6 \sigma_{\text {spat }}(\lambda)$ for the Hawaii - MOBY buoy site (solid black line) and its components on three different GSD: $210 \mathrm{~m}$ ( $p$-value: 0.0231$), 1050 \mathrm{~m}$ ( $p$-value: 0.0309$)$, and $2250 \mathrm{~m}$ ( $p$-value: $0.0185)$; the black dashed line is the fitting from Eq. (5). $k$ values $(1050 \mathrm{~m}): k_{a}=0.0139$; $k_{s}=0.0936 ; k_{g} \approx 0 ; k_{R_{\mathrm{rs}}} \approx 0$.

Since there were no clear differences in the dependence of $k$ coefficients on wind speed, changes of the fitting $k$ coefficients as a function of GSD averaged over all wind speeds are shown in Fig. 8 for OLI.

The main outcomes from the application of Eqs. (5) and (6) of the model to OLI data at all considered sites are as seen in Figs. 8 and 9. In the open ocean waters (Hawaii area), the main contributions come from the surface effects gradually increasing from small values at small GSDs to $k_{s}=0.1$ to 0.12 after about $1500 \mathrm{~m}$. Recalling that the surface effect itself was considered the sky normalized radiance multiplied by the average surface reflectance coefficient 
Estrella et al.: Spectral decomposition of remote sensing reflectance variance...
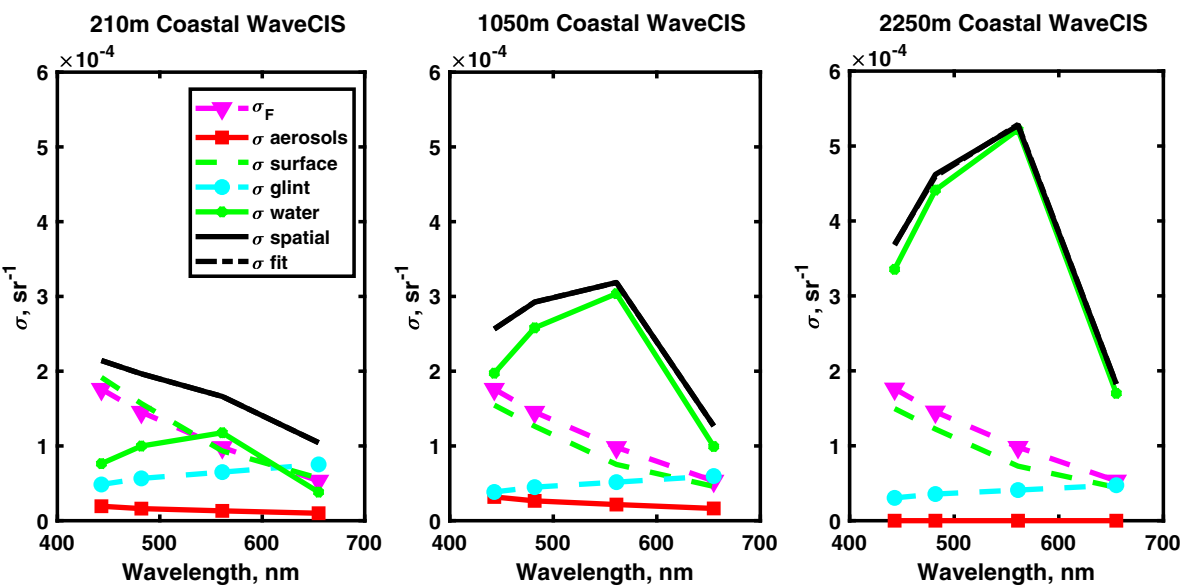

Fig. $7 \sigma_{\text {spat }}(\lambda)$ for the site near WaveCIS station (solid black line) and its components on three different GSD: $210 \mathrm{~m}$ ( $p$-value: 1.4044E-06), $1050 \mathrm{~m}$ ( $p$-value: 2.4854E-06), and $2250 \mathrm{~m}$ ( $p$-value: 7.2399E-05); the black dashed line is the fitting from Eq. (5). $k$ values $(1050 \mathrm{~m}): k_{a}=0.0051$; $k_{s}=0.1081 ; k_{g}=0.0104 ; k_{R_{\mathrm{rs}}}=0.0544$.
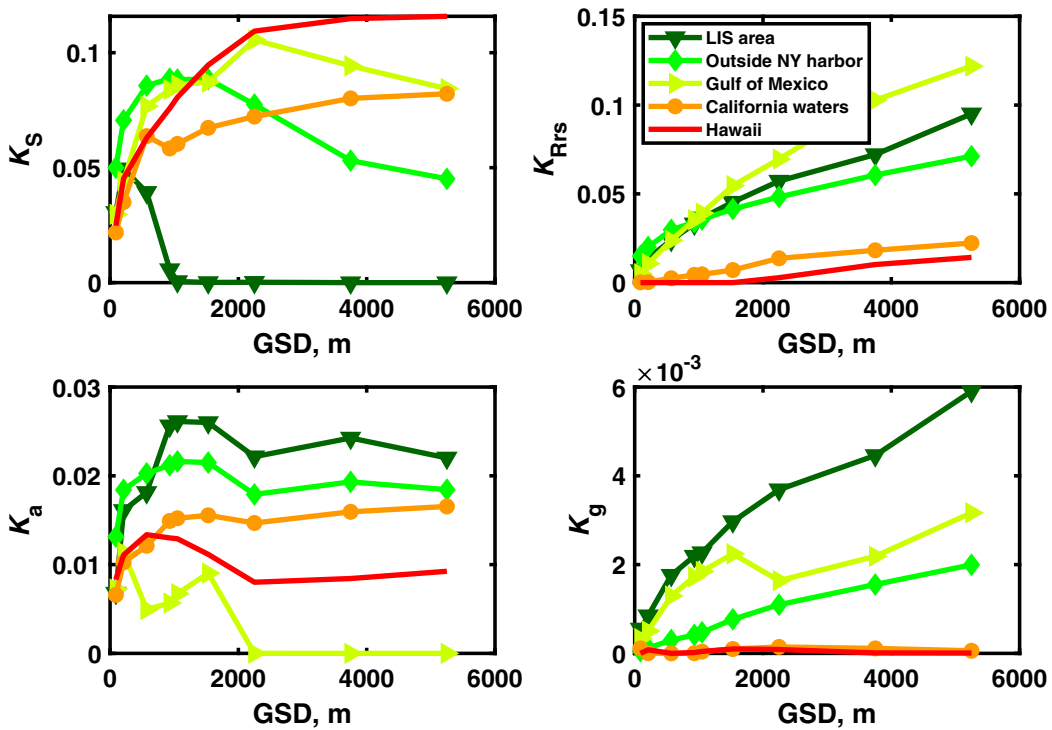

Fig. 8 Dependence of $k$ coefficients on GSD for all areas of study averaged over wind speed ranges for OLI.
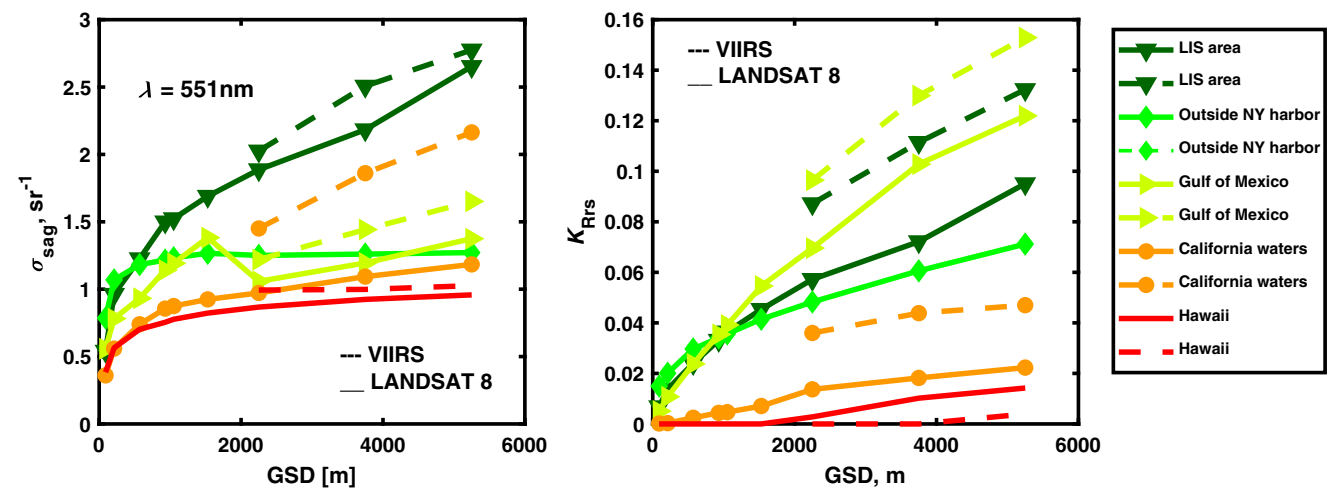

Fig. 9 Dependence of $\sigma_{\mathrm{sag}}(551)$ and $k_{R_{\mathrm{rs}}}$ on GSD for all areas of study averaged over wind speed ranges for OLI (solid lines) and VIIRS (dashed lines). 
$0.025, k_{s}=0.1$ corresponds to $10 \%$ changes in this value. There were also contributions from the aerosol component through $k_{a}=0.008$ to 0.015 , with its relative impact being visible in Fig. 6. There is not any spatial variability in Hawaii waters until GSD of about $1500 \mathrm{~m}$, and it is very small at larger distances in terms of the $k_{R_{\mathrm{rs}}}$ coefficient. Glint effects were not visible in open ocean waters.

In coastal waters, surface effects are smaller than in the open ocean and vary from site to site with average $k_{s}$ being about 0.06 and larger contributions typically being from the aerosol component $k_{a} \approx 0.02$, with some exceptions. As a reminder, in Eq. (6c), the glint mean value was determined based on $L_{G N}=0.005$, so $k_{g}=0.02$ to 0.05 represents $2 \%$ to $5 \%$ of this value. The most prominent effect is seen from the water variability with $k_{R_{\mathrm{rs}}}$ changing approximately proportionally to GSD and reaching about $7 \%$ to $14 \%$ at about $5000 \mathrm{~m}$.

Due to different NIR wavelengths being used in the atmospheric correction models for OLI and VIIRS and different viewing angles, a good match among the $k_{s}, k_{a}, k_{g}$ coefficients for these two sensors was not expected. To analyze the consistency of $\sigma_{\text {spat }}$ components for two sensors, a combined variance $\sigma_{\text {sag }}^{2}$ ("s" for the surface, "a" for aerosols, and "g" for glint in the subscript) was calculated as $\sigma_{\text {sag }}^{2}=\sigma^{2}-\sigma_{\text {water }}^{2}=\sigma^{2}-\left(k_{\mathrm{Rrs}} R_{\mathrm{rs}}\right)^{2}$ with the results of comparison for $551 \mathrm{~nm}$ shown in Fig. 9 together with $k_{\mathrm{Rrs}}$ for both sensors; a reasonable similarity with the smallest $\sigma_{\mathrm{sag}}$ in Hawaii and the largest in the LISCO area is demonstrated. A very small $k_{R_{\mathrm{rs}}}$ in the open ocean and an approximately linear increase with GSD in coastal waters are consistent for both sensors.

Examples of OLI processing in the Hawaii, WaveCIS, and LISCO areas are shown in Figs. 10-12, respectively. In addition to the mean $R_{\mathrm{rs}}(\lambda)$ (first column), $\sigma_{\text {spat }}(\lambda)$ spectra are shown for the spatial resolution 90 to $5250 \mathrm{~m}$ (column 2) and CVs were calculated as a function of GSD and spectrally (columns 3 and 4). OLI observes scenes almost vertically, so the dependence of GSD on the viewing angle is small and was not considered. Three rows in each figure correspond to wind speed ranges $W<3 \mathrm{~m} / \mathrm{s}, 3<W<5 \mathrm{~m} / \mathrm{s}$, and $W>5 \mathrm{~m} / \mathrm{s}$. CVs are presented in two forms: as $\sigma_{\text {spat }}(\lambda) / R_{\mathrm{rs}}(\lambda)$, which includes all effects, and as $k_{R_{\mathrm{rs}}}(\lambda)=\sigma_{\mathrm{water}}(\lambda) / R_{\mathrm{rs}}(\lambda)$, which is directly related to the water variability.
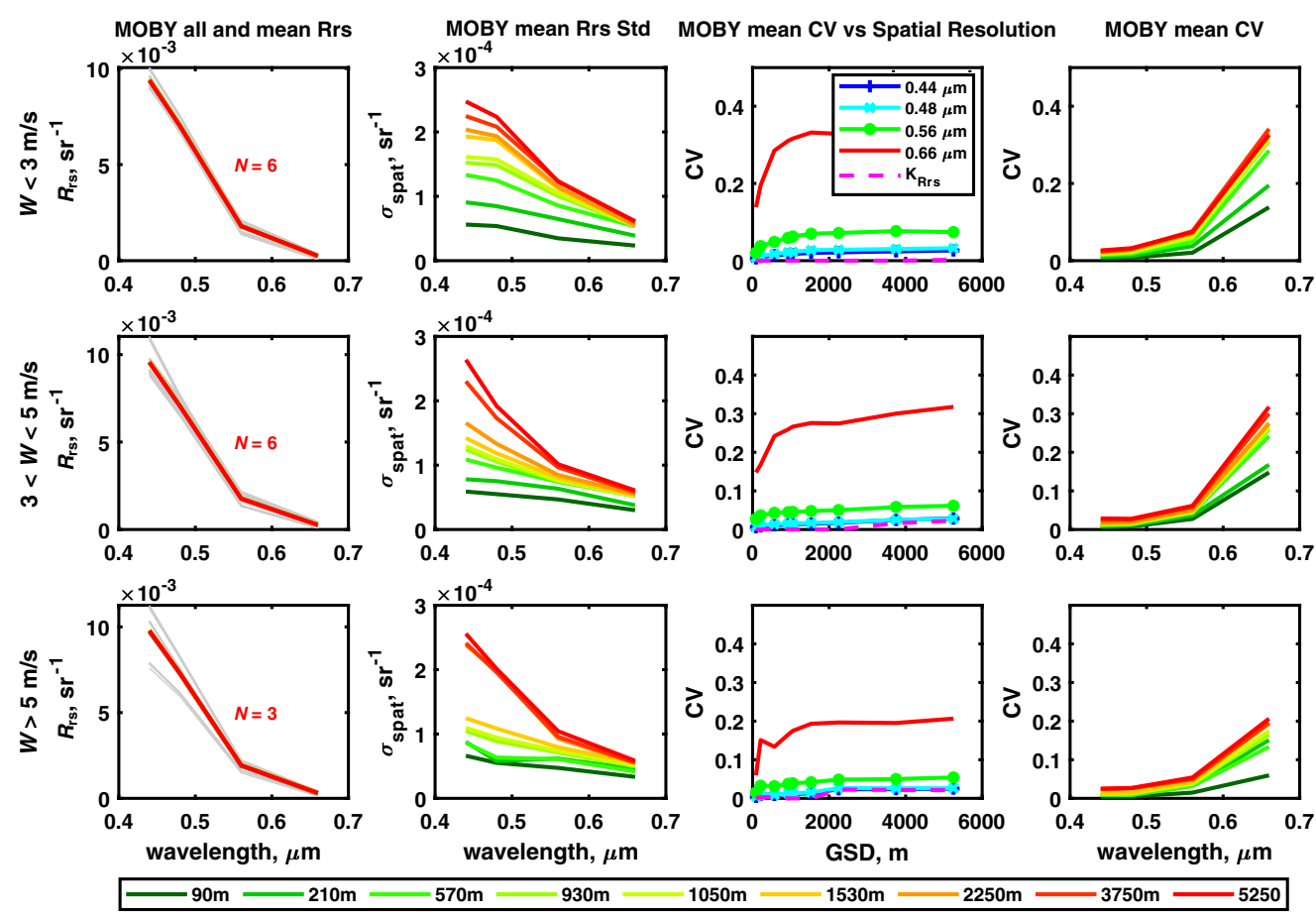

Fig. 10 Hawaii-near MOBY site, $R_{r s}$ spectra (gray) with their mean values for all GSD (column $1), \sigma_{\text {spat }}(\lambda)$ spectra for different spatial resolution (column 2), CV $=f(G S D)$ relationship by spectral band and $k_{R_{\mathrm{rs}}}$ (column 3), and CV spectra for different spatial resolution (column 4). Data were analyzed using three wind speed $(W)$ intervals: $W<3 \mathrm{~m} / \mathrm{s}$ (row 1 ), $3<W<5 \mathrm{~m} / \mathrm{s}$ (row 2 ), and $W>5 \mathrm{~m} / \mathrm{s}$ (row 3 ). 
Estrella et al.: Spectral decomposition of remote sensing reflectance variance...
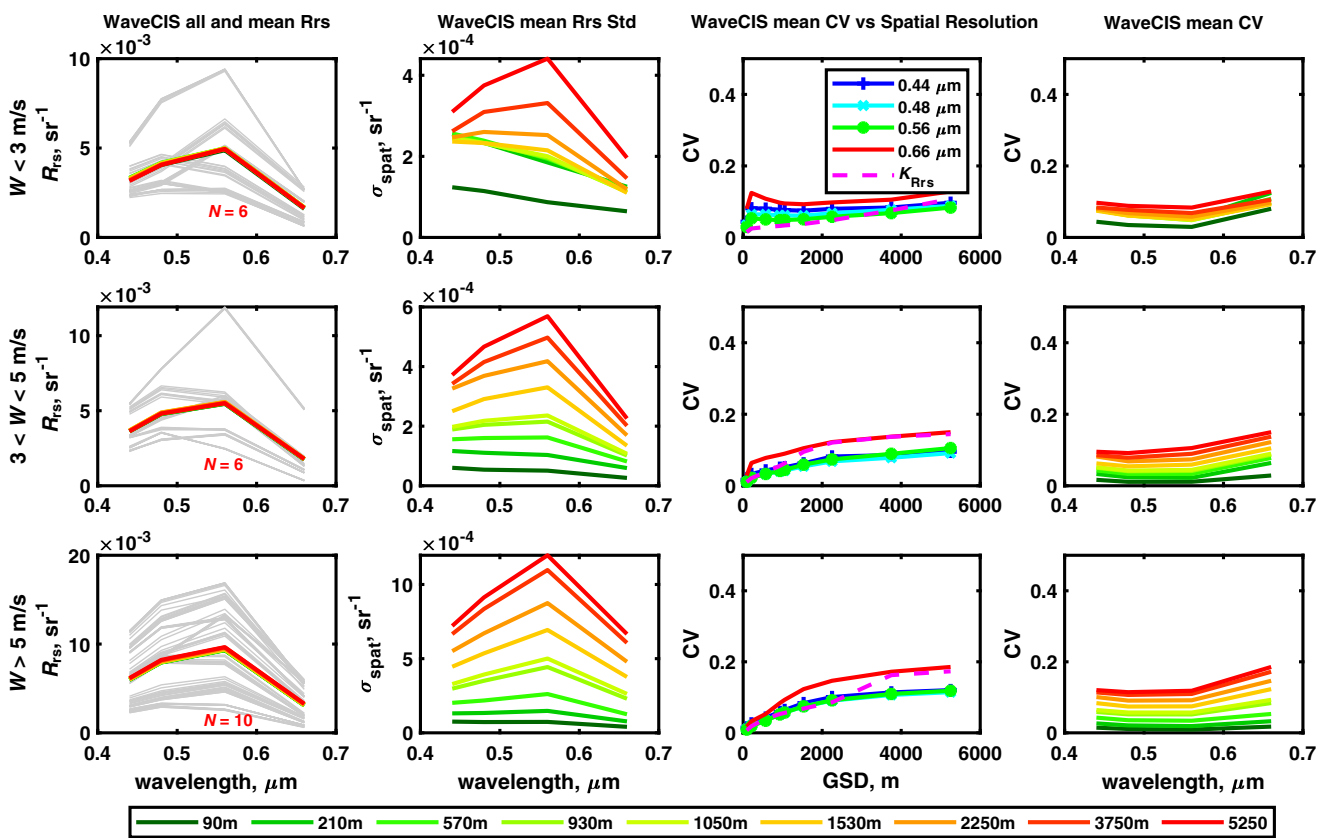

Fig. 11 Same as in Fig. 10 but for the WaveCIS station.

Very clear waters in the Hawaii area are represented by the station near the MOBY site with spectra shown in Fig. 10 with specific shapes of $\sigma_{\text {spat }}(\lambda)$, small CVs, and changes in CV values occurring at low GSD below $\sim 500 \mathrm{~m}$, which then become constant for larger GSD. At the same time, $k_{R_{\mathrm{rs}}}(\lambda)$ at this station, as was shown above, is almost equal to zero, meaning that all CVs are related to effects other than water variability.

In the WaveCIS coastal area (Fig. 11), the impact of water variability is much stronger than in the open ocean waters, and $k_{R_{\mathrm{rS}}}$ is in a similar range as $\mathrm{CVs}$ with some differences depending on the wavelength and wind speed. In the LISCO area (Fig. 12), surface and glint effects are much more pronounced than at WaveCIS (see Fig. 5), and $k_{R_{\mathrm{rs}}}$ is usually smaller than CV for all wavelegths. The Moses et al. ${ }^{22}$ curve determined for LISCO based on the variability of the water
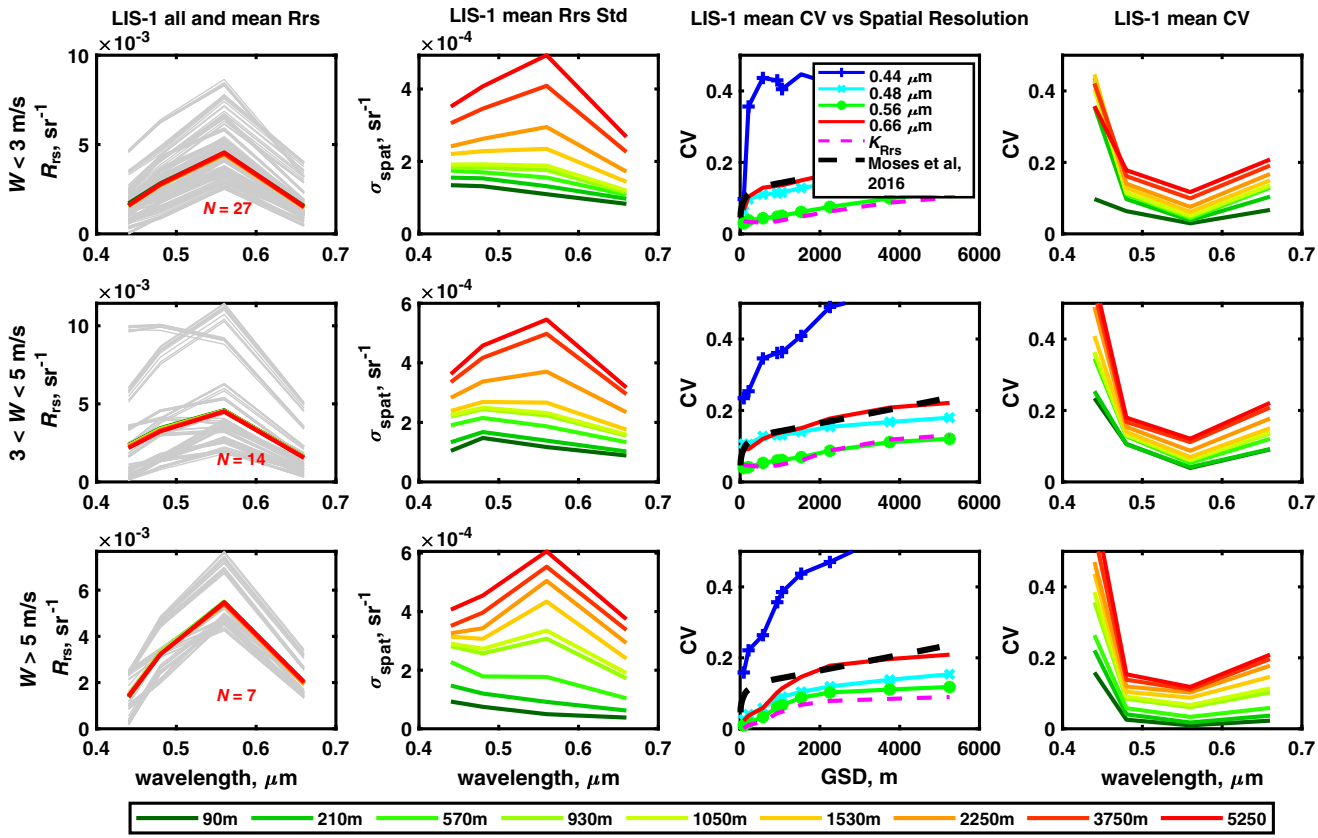

Fig. 12 Same as in Fig. 10 but for the LIS-station 1. 
absorption at $440 \mathrm{~nm}$ is close to the CV dependence on GSD for the blue band (at least for low and high wind speeds) and is higher than $k_{R_{\mathrm{rs}}}$.

\section{Conclusions}

A model was developed to estimate the contribution of the main components that play a role in atmospheric correction, to the variance spectra of remote sensing reflectance $\sigma^{2}(\lambda)$ in different water types. The model was applied to determine the spectral structure of remote sensing reflectance variances due to the spatial variability $\sigma_{\text {spat }}^{2}(\lambda)$ and their dependence on GSD based on satellite imagery from SNPP-VIIRS and Landsat 8-OLI sensors. It was shown that, in the open ocean, there was practically no water variability up to GSD of about $1500 \mathrm{~m}$, it remained low for larger GSD, and $\sigma_{\text {spat }}(\lambda)$ was found to be governed mostly by surface and aerosol components. In coastal waters, on average, there were similar variance contributions from surface and aerosol components, whereas water variability played a dominant role and increased proportionally to GSD. The coefficient, $k_{R_{\mathrm{rs}}}$, which characterizes water variability, was typically smaller than CV determined directly as $\sigma_{\text {spat }}(\lambda) / R_{\mathrm{rs}}(\lambda)$, and therefore water variability cannot be accurately determined from the latter ratio, which is due to the full spatial variability $\sigma_{\text {spat }}(\lambda)$. Relationships shown in Figs. 8 and 9 allow for estimating these differences. The differences are especially pronounced in the blue bands, where the contributions of surface and aerosol effects are larger.

\section{Acknowledgments}

This study was supported by NOAA CESSRST Grant NA16SEC4810008 as well by NOAA JPSS Cal/Val, JPSS PGRR programs, NASA OBB grants NNX16AR46G and 80NSSC21K0562, and the Office of Naval Research. We thank the USGS Processing Group and NASA OBPG for the satellite imagery, the Graduate Center of the City University of New York, The City College of New York, NOAA Center for Earth System Sciences and Remote Sensing Technologies, and NOAA Office of Education, Educational Partnership Program for fellowship support for Eder Herrera Estrella. The statements contained within the research article are not the opinions of the funding agency or the U.S. government but reflect the authors' opinions. Disclosures: The authors declare no conflicts of interest.

\section{References}

1. IOCCG, "Why ocean colour? The societal benefits of ocean colour technology," in Reports of International Ocean-Color Coordinating Group, No. 7, T. Platt et al., Eds., IOCCG, Dartmouth (2008).

2. C. D. Mobley, Light and Water: Radiative Transfer in Natural Waters, Academic Press, San Diego, California (1994).

3. E. Berdalet et al., "Marine harmful algal blooms, human health and wellbeing: challenges and opportunities in the 21st century," J. Marine Biol. Assoc. U. K. 96(1), 61-91 (2015).

4. H. R. Gordon and A. Y. Morel, Remote Assessment of Ocean Color for Interpretation of Satellite Visible Imagery: A Review, p. 114, Springer-Verlag, New York (1983).

5. IOCCG, "Uncertainties in ocean colour remote sensing," in Reports of International OceanColor Coordinating Group, No. 18, F. Mélin, Ed., IOCCG, Dartmouth (2019).

6. H. R. Gordon and M. Wang, "Retrieval of water-leaving radiance and aerosol optical thickness over the oceans with SeaWiFS: a preliminary algorithm," Appl. Opt. 33(3), 443-452 (1994).

7. Z. Ahmad et al., "New aerosol models for the retrieval of aerosol optical thickness and normalized water-leaving radiances from the SeaWiFS and MODIS sensors over coastal regions and open oceans," Appl. Opt. 49(29), 5545-5560 (2010).

8. H. R. Gordon and M. Wang, "Surface-roughness considerations for atmospheric correction of ocean color sensors. I: The Rayleigh-scattering component," Appl. Opt. 31(21), 42474260 (1992). 
9. M. Wang and S. W. Bailey, "Correction of sun glint contamination on the SeaWiFS ocean and atmosphere products," Appl. Opt. 40(27), 4790-4798 (2001).

10. R. Frouin, M. Schwindling, and P. Y. Deschamps, "Spectral reflectance of sea foam in the visible and near-infrared: in situ measurements and remote sensing implications," J. Geophys. Res., 101(C6), 14361-14371 (1996).

11. C. Carrizo et al., "Characterization of radiance from the ocean surface by hyperspectral imaging," Opt. Express 27(2), 1750-1768 (2019).

12. P. M. M. Groetsch et al., "Validation of a spectral correction procedure for sun and sky reflections in above-water reflectance measurements," Opt. Express 25(16), A742-A761 (2017).

13. P. M. M. Groetsch, R. Foster, and A. Gilerson, "Exploring the limits for sky and sun glint correction of hyperspectral above-surface reflectance observations," Appl. Opt. 59(9), 29422954 (2020).

14. J. Wei et al., "Improving low-quality satellite remote sensing reflectance at blue bands over coastal and inland waters," Remote Sens. Environ. 250, 112029 (2020).

15. J. Li et al., "The error budget in the validation of radiometric 2 products derived from OLCI around the China Sea 3 from open ocean to coastal waters compared with 4 MODIS and VIIRS," Rem. Sens. 11(20), 2400 (2019).

16. C. Hu, L. Feng, and Z. Lee, "Uncertainties of SeaWiFS and MODIS remote sensing reflectance: implications from clear water measurements," Remote Sens. Environ. 133, 168-182 (2013).

17. G. Zibordi et al., "AERONET-OC: a network for the validation of ocean color primary products," J. Atmos. Ocean Technol. 26(8), 1634-1651 (2009).

18. N. Pahlevan et al., "ACIX-Aqua: a global assessment of atmospheric correction methods for Landsat-8 and Sentinel-2 over lakes, rivers, and coastal waters," Remote Sens. Environ. 258, 112366 (2021).

19. T. S. Moore, J. W. Campbell, and H. Feng, "Characterizing the uncertainties in spectral remote sensing reflectance for SeaWiFS and MODIS-Aqua based on global in situ matchup data sets," Remote Sens. Environ. 159, 14-27 (2015).

20. M. Ondrusek et al., "Report for dedicated JPSS VIIRS Ocean color calibration/validation Cruise September 2019," NOAA Library, NOAA Technical Report NESDIS 154 (2021).

21. B. Franz and E. Karaköylü, "Estimating uncertainty in the retrieval of water-leaving reflectance from spaceborne ocean color sensors: effect of instrument noise," in Proc. Ocean Opt. XXIII (2016).

22. W. J. Moses et al., "Spatial scales of optical variability in the coastal ocean: implications for remote sensing and in situ sampling," J. Geophys. Res. Oceans, 121, 4194-4208 (2016).

23. E. H. Estrella et al., "Blue band reflectance uncertainties in coastal waters and their impact on retrieval algorithms," Proc. SPIE 11420, 1142006 (2020).

24. C. Cox and W. Munk, "Measurement of the roughness of the sea surface from photographs of the sun's glitter," J. Opt. Soc. Am. 44(11), 838-850 (1954).

25. L. Qi et al., "Requirement of minimal signal-to-noise ratios of ocean color sensors and uncertainties of ocean color products," J. Geophys. Res. Oceans 122(3), 2595-2611 (2017).

26. A. Gilerson et al., "Characterization of aerosol parameters over ocean from the Ocean Color satellite sensors and AERONET-OC data," Proc. SPIE 10422, 104220H (2017).

27. H. H. Tynes et al., "Monte Carlo and multicomponent approximation methods for vector radiative transfer by use of effective Mueller matrix calculations," Appl. Opt. 40(3), 400-412 (2001).

28. X. Xiong et al., "MODIS and VIIRS calibration and characterization in support of producing long-term high-quality data products," Remote Sens. 12(19), 3167 (2020).

29. R. Morfitt et al., "Landsat-8 Operational Land Imager (OLI) radiometric performance on-orbit," Remote Sens. 7(2), 2208-2237 (2015).

30. D. Marquardt, "An algorithm for least-squares estimation of nonlinear parameters," J. Soc. Ind. Appl. Math. 11(2), 431-441 (1963).

31. K. Levenberg, "A method for the solution of certain non-linear problems in least squares," Q. Appl. Math. 2, 164-168 (1944). 
32. D. A. Siegel et al., "Atmospheric correction of satellite ocean color imagery: the black pixel assumption," Appl. Opt. 39(21), 3582-3591 (2000).

33. S. W. Bailey, B. A. Franz, and P.J. Werdell, "Estimation of near-infrared water-leaving reflectance for satellite ocean color data processing," Opt. Express 18(7), 7521-7527 (2010).

34. NASA Goddard Space Flight Center, Ocean Ecology Laboratory, Ocean Biology Processing Group, Visible and Infrared Imager/Radiometer Suite (VIIRS) Ocean Color Data, 2018 Reprocessing, NASA OB.DAAC, Greenbelt, Maryland (accessed 16 June 2021).

35. S. Hlaing et al., "Evaluation of the VIIRS ocean color monitoring performance in coastal regions," Rem. Sens. Environ. 139, 398-414 (2013).

36. USGS, "EROS science processing architecture on demand interface," https://espa.cr.usgs .gov/index/ (2020).

37. N. Pahlevan et al., "Landsat 8 remote sensing reflectance (Rrs) products: evaluations, intercomparisons, and enhancements," Remote Sens. Environ. 190, 289-301 (2017).

38. B. A. Franz et al., "Ocean color measurements with the Operational Land Imager on Landsat-8: implementation and evaluation in SeaDAS," J. Appl. Rem. Sens. 9(1), 096070 (2015).

39. Y. Fan et al., "OC-SMART: a machine learning based data analysis platform for satellite ocean color sensors," Remote Sens. Environ. 253, 112236 (2021).

Eder Herrera Estrella is an NOAA EPP Earth System Sciences and Remote Sensing Scholar pursuing his $\mathrm{PhD}$ in earth and environmental sciences at the Graduate Center, CUNY. He received his BS and MS degrees in environmental engineering in 2017 and 2018, respectively. He has been a research assistant in the Optics Remote Sensing Laboratory at the City College of New York, CUNY, since 2015. His work contributes to the understanding of uncertainties of remote sensing reflectance from satellite sensors in coastal regions.

Biographies of the other authors are not available. 